\title{
AVALIAÇ̃̃O DO COMPORTAMENTO DE OVINOS SANTA INÊS EM SISTEMA SILVIPASTORIL NO NORTE FLUMINENSE
}

\author{
Evaluation of the behaviour of Santa Inês sheep in a silvopastoral system in \\ the north of Rio de Janeiro state
}

\author{
Rony Antonio Ferreira ${ }^{1}$, Luis Humberto Castillo Estrada², José Tarcísio Lima Thiébaut ${ }^{2}$, \\ Luis Bernabé Castillo Granados ${ }^{3}$, Vilmar Rodrigues de Souza Júnior ${ }^{4}$
}

\begin{abstract}
RESUMO
Um estudo foi desenvolvido em Quissamã, RJ utilizando-se 20 ovelhas da raça Santa Inês com idade média de dois anos objetivando-se avaliar o comportamento dos animais em dois sistemas de criação. Os animais foram mantidos em piquetes com pastagem de capim-quicuio, sendo dez ovelhas alojadas em piquete sem sombreamento e outras 10 alojadas em piquete, com consórcio de pastagem e o cultivo de coco (Cocus nucifera). Durante o período de 10 dias consecutivos, os animais tiveram seus respectivos comportamentos observados de acordo com o tempo despendido com as atividades de alimentação, ruminação e ócio, aferidos de dez em dez minutos das 9:00 às 17:00 horas, período em que permaneciam a pasto. Os animais expostos ao sol despenderam menor tempo diário pastejando, aumentando atividade de ruminação e ócio, mantendo essas atividades menos constantes quando comparadas aos animais mantidos à sombra. O consórcio da cultura de coco com a pastagem influenciou positivamente o comportamento dos animais.
\end{abstract}

Termos para indexação: Bem estar, comportamento, sistema de criação.

\section{ABSTRACT}

A study was developed in Quissamã, RJ, Brazil, with twenty two-year-old sheep of the Santa Inês with the objective of evaluating the animals' behavior in two raising system. The animals were maintained in two pickets with "capim-quicuio" pasture. The animals were separated in two groups, ten of which without shade and the other ten in a picket with a consortium of pasture and a coconut cultivation (Cocus nucifera). During a period of ten consecutive days, the animals had their behavior evaluated according to the time spent on feeding, rumination and resting time, checked every ten minutes, from 9 a.m. to 5 p.m. The animals exposed to sunlight spent less time grazing, increased rumination time and resting time, and these activities were less stable when compared to the sheep under shade. Coconut cultivation, therefore, had a positive impact on the behavior of the animals.

Index terms: Welfare, bahaviour, raising system.

(Recebido em 31 de julho de 2008 e aprovado em 28 de abril de 2010)

\section{INTRODUÇÃO}

A exploração de ovinos deslanados no Brasil está amplamente distribuída por todo país, principalmente na região Nordeste, onde teve origem a raça Santa Inês. A ovinocultura na região Sudeste do Brasil vem crescendo muito nos últimos anos. No estado do Rio de Janeiro existe uma população de cerca de 12.000 animais, prevalecendo os animais deslanados da raça Santa Inês. De acordo com (Figueiredo et al., 1990), a Santa Inês é descendente de animais das raças Bergamácia (lanada), Morada Nova (deslanada) e Crioula do Nordeste.

As condições ambientais propícias, aliadas à ampla disponibilidade de terras, principalmente nas fronteiras em expansão do semiárido nordestino e das regiões centrooeste e norte do país, propiciam baixos custos de produção em comparação com outras regiões do país, favorecendo esse tipo de atividade. Porém, os sistemas de produção de ovinos têm sido pouco estudados no Brasil, principalmente, nas regiões com menor tradição ovinícula, como é o caso da região sudeste, particularmente, da mesorregião Norte Fluminense.

A produção de ovinos experimenta atualmente, avanços tecnológicos que abrangem desde a criação em si, como também agregação de valor pelo processamento de carne e estudos de mercado com a finalidade de atender à demanda do consumidor moderno, que exige qualidade do produto final associado ao bem-estar animal.

\footnotetext{
'Universidade Federal dos Vales do Jequitinhonha e Mucuri/UFVJM - Departamento de Zootecnia/DZO - MGT 367 - km 583 - 5000 - Campus JK 39100-000 - Diamantina, MG - ronyufvjm@gmail.com

2Universidade Estadual do Norte Fluminense Darcy Ribeiro/UENF - Centro de Ciências e Tecnologias Agropecuárias/CCTA - Campos dos Goytacazes, RJ ${ }^{3}$ Fundação Estadual Norte Fluminense/FENORTE - Campos dos Goytacazes, RJ
}

${ }^{4}$ Universidade Federal dos Vales do Jequitinhonha e Mucuri/UFVJM - Diamantina, MG 
Além disso, alguns fatores importantes como as variações ambientais, foram pouco observados nas pesquisas conduzidas com ovinos (Andrade et al., 2007). $\mathrm{O}$ ambiente deve ser considerado ao se estudar o comportamento animal, independentemente do sistema de criação, uma vez que o consumo de matéria seca, ingestão de água e desempenho dos animais recebem influência direta do clima e da hierarquia social do grupo.

Mudanças estão acontecendo no cenário mundial na produção de ruminantes, onde estão sendo implantados sistemas de produção que visam o aproveitamento sustentável e o bem-estar animal. O bem-estar animal pode ser considerado uma demanda para qualquer sistema criatório que deseja ser eticamente defensável e socialmente aceitável. De acordo com (Warriss, 2000), as pessoas desejam produtos com "qualidade ética", isso é, animais que tenham sido criados, tratados e abatidos em sistemas que promovam o bem-estar, mas que também sejam sustentáveis e ambientalmente corretos.

O sistema agrossilvipastoril consiste no aproveitamento de uma área comum para mais de uma produção, ou seja, uma combinação de plantação de árvores, madeireiras ou frutíferas, com animais na mesma área, visando aumentar a eficiência de utilização dos recursos naturais com a manutenção do equilíbrio do ecossistema. O caráter ecológico dessa associação é um dos princípios que regem esse sistema de produção.

$\mathrm{Na}$ região Norte Fluminense existem diversas propriedades rurais cuja fonte principal de renda é a cultura do coco, com características agrícolas que possibilitam o consórcio com criação de animais, destacando-se a ovinocultura. Um estudo foi realizado objetivando-se avaliar os efeitos do consórcio (coco x ovinos), sobre o comportamento dos animais.

\section{MATERIAL E MÉTODOS}

O experimento foi conduzido na Fazenda Capão Grande, no município de Quissamã, RJ localizada na mesorregião Norte Fluminense, no período de setembro a outubro, utilizando-se 20 ovelhas da raça Santa Inês, com peso médio de $40 \mathrm{~kg}$, com idade média de dois anos.

Caracterizando o primeiro tratamento, 10 animais foram mantidos em piquete com pastagem de capim-quicuio (Pennisetum clandestinum Hochst. cv. Comum) e área de $20.000 \mathrm{~m}^{2}$ sendo mantidos a céu aberto, sem sombreamento natural ou artificial. No segundo tratamento, 10 animais foram mantidos em piquete com as mesmas características de pastagem e área do primeiro tratamento, porém, consorciado com a cultura de coco (Cocus nucifera L.), plantas em fase de produção cultivadas em espaçamento 8,5 x 10 m. Em cada piquete, os animais receberam água e sal mineralizado à vontade. A disponibilidade de forragem era semelhante em ambos os tratamentos (piquetes).

Os animais foram mantidos nos respectivos piquetes (sem rotação) das 9:00 às 17:00 h (coleta de dados de comportamento) e depois recolhidos em aprisco.

Antes do início da tomada de dados, os animais passaram por um período de 10 dias de adaptação às condições experimentais e permaneceram no local de estudo até a conclusão do experimento. Como apresentado por Swenson \& Reece (1996), a permanência de apenas quatro dias em ambientes com temperaturas diferenciadas é suficiente para promover adaptação fisiológica do organismo animal ao novo ambiente térmico.

Os animais foram identificados em cada tratamento por numeração feita no dorso com tinta, com colares numerados e fitas de tecido de cores diferenciadas para facilitar a observação dos mesmos.

O padrão comportamental foi avaliado simultaneamente por dois observadores, um em cada ambiente, durante um período de dez dias consecutivos com observações a cada 10 minutos, durante oito horas ininterruptas (das 9:00 as 17:00), de modo a caracterizar observação dirigida (Ferreira, 2005), sem influenciar o repertório comportamental natural dos animais e o manejo adotado na propriedade. Para caracterização comportamental foram identificados os tempos despendidos com as atividades de pastejo, ócio e ruminação.

A observação realizada em cada indivíduo constituiu uma amostra simples ao acaso para análise da proporção ou porcentagem de cada atividade, em relação ao período total de observação. As amostras foram dimensionadas, considerando uma população infinita das três atividades, com um desvio de mais ou menos $10 \%$ em torno da proporção amostral média.

Para a caracterização do ambiente térmico no período de avaliação do comportamento dos animais, foram utilizados quatro conjuntos compostos por um termômetro de máxima e mínima, termômetro de globo negro e termohigrômetro localizados à meia altura do corpo dos animais, em pontos estratégicos de modo a representar o ambiente. As leituras dos termômetros foram realizadas em intervalos de uma hora, durante a observação comportamental. Os resultados das leituras foram utilizados para calcular o ITGU (índice de temperatura de globo e umidade).

Para não influenciar na observação comportamental dirigida, ao final do período experimental, os animais permaneceram em seus respectivos ambientes, sendo 
escolhido aleatoriamente um indivíduo em cada tratamento para mensuração da temperatura retal em intervalos de uma hora de 9:00 às 17:00 horas.

A análise estatística foi realizada considerando os animais em cada período, sendo o período I (9:00 às 11:00 horas), período II (11:00 às 14:00 horas) e período III (14:00 às 17:00 horas), no piquete sol e no piquete sombra. Foram obtidos intervalos de confiança, para proporção populacional de cada atividade a fim de verificar, estatisticamente, o comportamento da raça Santa Inês.

Para todas as atividades e animais, em todas as situações possíveis, após o dimensionamento amostral, foram obtidos intervalos de confiança por animal, período e animal e no confundimento de animais (entre todos os animais), e a amostra considerada sempre foi representativa de população infinita e os períodos I, II e III, em todas as condições estabelecidas apresentaram intervalos superpostos a $95 \%$ de probabilidade. Ambos os períodos, também em todas as situações, tiveram os intervalos não superpostos um ao outro.

$$
\begin{gathered}
\mathrm{p}_{\mathrm{i}}=\sum_{\mathrm{i}, \mathrm{j}, \mathrm{k}} \mathrm{X}_{\mathrm{i}, \mathrm{k}} \quad \text { para } \mathrm{i}=1,2,3 \\
\mathrm{n}_{\mathrm{ij}} \\
\text { onde: } \\
\mathrm{i}=1 \text { alimentação } \\
\mathrm{i}=2 \text { ruminação } \\
\mathrm{i}=3 \text { ócio }
\end{gathered}
$$

$$
\text { pij }-t_{t a b} v V_{(} p_{i j}=P_{i j}=p_{i}+t_{t a b} v V_{(p i j)}
$$

\section{RESULTADOS E DISCUSSÃO}

Os resultados de temperatura de bulbo seco $\left({ }^{\circ} \mathrm{C}\right)$, temperatura de globo negro $\left({ }^{\circ} \mathrm{C}\right)$ e de umidade relativa $(\%)$ observados durante o período experimental, assim como os valores calculados de índice de temperatura de globo e umidade (ITGU), para os ambientes de sol e de sombra, estão descritos na Tabela 1. O comportamento ambiental ao longo do dia (ITGU) está descrito na Figura 1. Pode-se observar que os valores de temperatura ambiental em ambos os sistemas de criação estavam acima da faixa de conforto térmico para a categoria de ovinos estudada. De acordo com (Baêta \& Souza, 1997), para ovinos a temperatura crítica inferior (TCI) está em torno de $-20^{\circ} \mathrm{C}$ e a temperatura crítica superior (TCS) em torno de $35^{\circ} \mathrm{C}$.

Apesar de ambos os ambientes de criação serem considerados estressantes pelo calor para os animais verifica-se, pelos resultados de ITGU calculados, que o sistema de criação à sombra propiciou menor estresse calórico aos animais, exigindo, portanto, menor esforço desses para manutenção de sua homeotermia.

De acordo com Beede \& Collier (1986), temperatura ambiente elevada, acima da zona de conforto, reduz o consumo de alimento, principalmente para aqueles com alto teor de fibra, como é o caso das pastagens de clima tropical, além de elevar a temperatura retal dos animais.

Na Tabela 2 observaram-se as proporções de tempo utilizadas pelos ovinos com atividades de alimentação, ruminação e ócio no período das nove às 17 horas mantidos em piquetes, com sol ou sombreado pela cultura do coco e na Figura 2, os valores de temperatura retal desses animais.

Ao se analisar as atividades desenvolvidas pelos animais, em porcentagem de tempo no período observado, verificou-se que os ovinos mantidos ao sol, dedicaram menor tempo diário à alimentação (pastejo) (83\%) em relação aos animais do piquete sombra (91\%). Os animais mantidos ao sol utilizaram normas de conduta para minimizar o ganho de calor por radiação solar, realizando atividades que demandam menor movimentação (ruminação e ócio).

O maior estresse ambiental, caracterizado pelos maiores valores de ITGU, sofrido pelos animais mantidos ao sol, foi o fator principal que determinou aos ovinos realizar tais normas de conduta. Esses resultados evidenciaram que animais com acesso à sombra dedicaram maior tempo às atividades de pastejo, permanecendo menor tempo em ócio.

Tabela 1 - Médias de temperatura de bulbo seco $\left({ }^{\circ} \mathrm{C}\right)$, temperatura de globo negro $\left({ }^{\circ} \mathrm{C}\right)$, umidade relativa $(\%)$ e índice de temperatura de globo e umidade (ITGU) observados nos piquetes com ovinos Santa Inês.

\begin{tabular}{ccc}
\hline Parâmetro ambiental & Sol & Sombra \\
\hline Bulbo seco $\left({ }^{\circ} \mathrm{C}\right)$ & $33,3 \pm 3,07$ & $31,7 \pm 3,12$ \\
Globo negro $\left({ }^{\circ} \mathrm{C}\right)$ & $37,9 \pm 5,07$ & $32,9 \pm 3,38$ \\
Umidade relativa $(\%)$ & $60,9 \pm 9,13$ & $63,3 \pm 8,25$ \\
ITGU & $87,0 \pm 5,43$ & $81,8 \pm 3,85$ \\
\hline
\end{tabular}




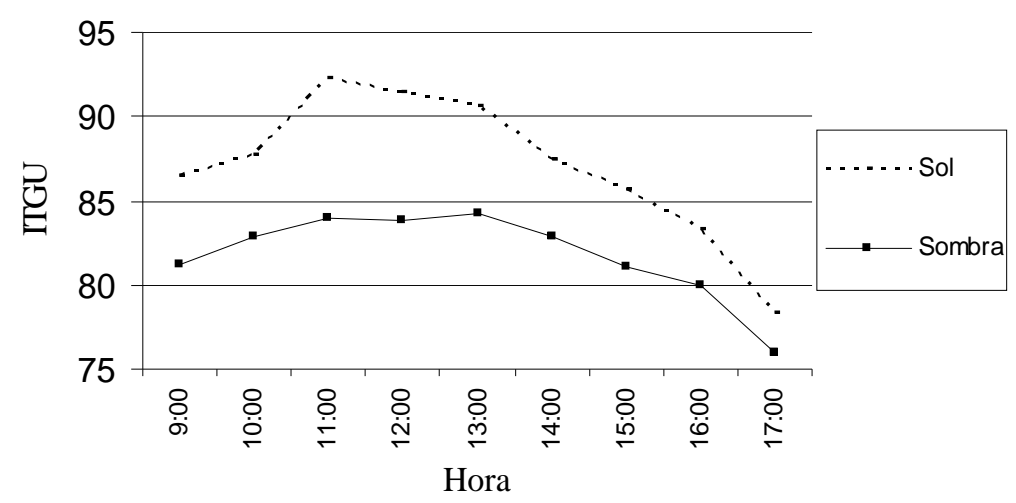

Figura 1 - Valores calculados de ITGU nas condições das pastagens no sol e na sombra e em diferentes horas do dia.

Tabela 2 - Comportamento de ovinos Santa Inês (em \% do tempo), mantidos em piquete com sol e em piquete, com sombra das 9 às 17 horas.

\begin{tabular}{ccccccc}
\hline Períodos (horas) & \multicolumn{3}{c}{ Comportamento ao Sol } & \multicolumn{3}{c}{ Comportamento ao Sol } \\
\cline { 2 - 7 } & Alimentando & rumimando & ócio & Alimentando & rumimando & Ócio \\
\hline Total (09 às 17) & $83,0 \pm 1,05$ & $9,1 \pm 0,80$ & $7,9 \pm 0,75$ & $91,6 \pm 0,77$ & $4,3 \pm 0,57$ & $4,0 \pm 0,54$ \\
\hline PI (09 às 11) & $91,4 \pm 1,58$ & $4,6 \pm 1,18$ & $4,0 \pm 1,10$ & $88,7 \pm 1,78$ & $6,6 \pm 1,40$ & $4,7 \pm 1,19$ \\
PII (11 às 14) & $70,0 \pm 2,06$ & $14,7 \pm 1,59$ & $15,3 \pm 1,61$ & $94,1 \pm 1,05$ & $3,4 \pm 0,81$ & $2,5 \pm 0,70$ \\
PIII (14 às 17) & $91,0 \pm 1,31$ & $6,2 \pm 1,11$ & $2,8 \pm 0,75$ & $91,0 \pm 1,32$ & $3,9 \pm 0,89$ & $5,1 \pm 1,01$ \\
\hline
\end{tabular}

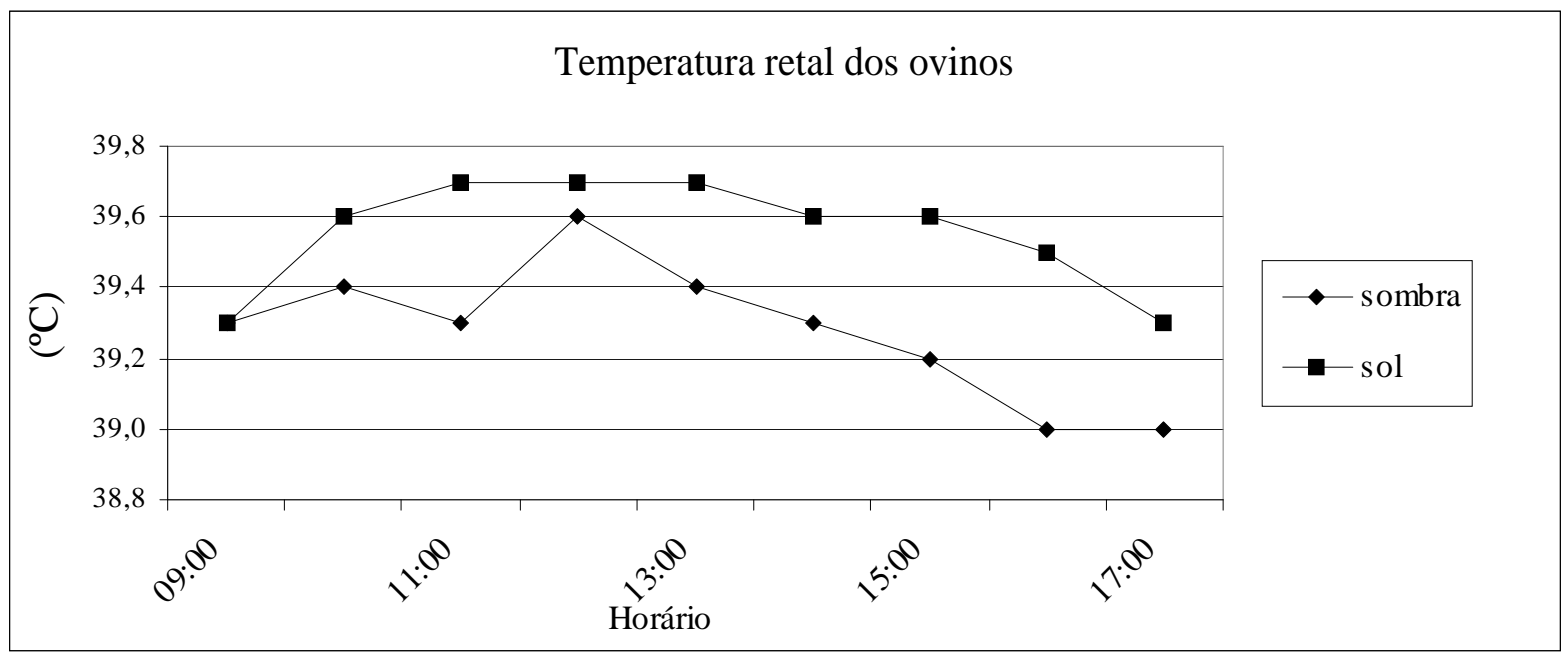

Figura 2 - Temperatura retal $\left({ }^{\circ} \mathrm{C}\right)$ de ovinos Santa Inês em piquetes com sombra e ao sol.

Os ovinos mantidos à sombra mantiveram suas atividades de alimentação, ruminação e ócio mais constantes durante o mesmo período. Em contraposição, os ovinos expostos ao sol, aumentaram atividade de ruminação e ócio.
Observa-se que os animais em alimentação ao sol, diminuíram em torno de $20 \%$ o pastejo, entre os horários de 11:00 às 14:00 (período II), quando experimentaram as maiores temperaturas corporais (Figura 2). Esse perfil comportamental corrobora os resultados obtidos por 
Cândido et al. (2004), que detectaram que o período do dia mais crítico para o pastejo compreende o intervalo de 11 às 14 horas. Nesse intervalo, observou-se que os animais procuravam se esconder junto à cerca, na tentativa de se refugiar do sol. Após esses horários, a atividade de alimentação retornou às condições observadas durante o inicio da manhã, quando as temperaturas são mais amenas, comportamento esse, que é acompanhado pela diminuição das temperaturas retais.

Em estudos com ovelhas Santa Inês os autores relataram que animais sem acesso à sombra, ficaram mais tempo em processo de ruminação e realizaram dois grandes períodos de pastejo, um logo ao amanhecer e outro um pouco antes do anoitecer e, entre o final da manhã e as primeiras horas da tarde, predominaram as atividades de ócio e ruminação Soest (1994).

Os animais mantidos ao sol, no período II (11:00 às 14:00 horas), dedicaram em torno de $14 \%$ de seu tempo para a atividade de ruminação e $15 \%$ para a atividade de ócio. Os animais expostos à sombra apresentaram um comportamento mais uniforme nas duas atividades em questão, ou seja, registraram no mesmo período, respectivamente para as atividades, apenas 3,4 e 2,5\% do tempo. A porcentagem de animais em pastejo e suas relações com o ambiente, ao longo do dia, determinam o tipo de comportamento alimentar. De acordo com Albright (1993), o ritmo da atividade de pastejo também varia com a radiação solar, temperatura e umidade relativa do ar afetando o consumo animal.

As se analisar os animais om acesso à sombra de coqueiro, pode-se observar que, no período crítico do dia (das 11:00 às 14:00), a atividade de alimentação não foi prejudicada pelo ambiente quente, sendo inclusive, melhorada. Os ovinos com acesso à sombra dedicaram maior tempo às atividades de pastejo, permanecendo menor tempo em ócio.

Ao considerar o período total de observação dos animais (10 dias), calculou-se que aqueles mantidos à sombra dedicaram à alimentação cerca de 73 horas e aqueles mantidos ao sol, 66 horas. Considerando que os animais mantidos ao sol pastejaram diariamente, por cerca de seis horas, ao final do período de observação, eles estavam defasados em um dia de pastejo, caso não conseguissem realizar a compensação de ingestão necessária. Além do aspecto produtivo, o bem-estar dos animais deve ser considerado em qualquer sistema de produção.

Os ovinos que tinham acesso à sombra, além da menor variação da atividade alimentar, apresentaram temperaturas retais inferiores àqueles mantidos ao sol, indicando menor intensidade de estresse por calor. Cabe citar que, mesmo na sombra, a maior temperatura observada nos animais foi entre 11:00 e 13:00 horas. Estes resultados vão de encontro aos de Andrade et al. (2007), que não evidenciaram benefício do fornecimento de sombra sobre a temperatura retal de ovinos da raça Santa Inês.

\section{CONCLUSÕES}

Ovinos Santa Inês mantidos em pastagem sombreadas pela cultura de coco (Cocus nucifera) apresentaram repertório comportamental mais constante ao longo do dia, sendo beneficiados em razão do menor estresse calórico.

\section{REFERÊNCIAS BIBLIOGRÁFICAS}

ALBRIGHT, J.L. Nutrition, feeding and calves: feeding behaviour of dairy cattle. Journal Dairy Science, Madison, v.76, p.485-498, 1993.

ANDRADE, I.S.; SOUZA, B.B.; PEREIRA FILHO, J.M. Parâmetros fisiológicos e desempenho de ovinos Santa Inês submetidos a diferentes tipos de sombreamento e a suplementação em pastejo. Ciência e Agrotecnologia, Lavras, v.31, n.2, p.540-547, mar./abr. 2007.

\section{BAÊTA, F.C.; SOUZA, C.F. Ambiência em edificações rurais e conforto térmico. Viçosa, MG: UFV, 1997. 246p.}

BEEDE, D.K.; COLLIER, R.J. Potencial nutricional strategies for intensively managed calttle during thermal stress. Journal of Animal Science, Champaign, v.62, n.2, p.543-554, 1986.

FERREIRA, R.A. Maior produção com melhor ambiente para aves, suínos e bovinos. Viçosa, MG: Aprenda Fácil, 2005. 374p.

FIGUEIREDO, E.A.P.; SHELTON, M.; BARBIERI, M.E. Available genetic resources: the origin and classification of the world's sheep. In: SHELTON, M.; FIGUEIREDO, E.A.P. (Eds.). Hair sheep production in tropical and subtropical regions. Davis: [s.n.], 1990. p.25-36.

SOEST, P.J. van. Nutritional ecology of the ruminant. Ithaca: Cornell University, 1994. 476p.

SWENSON, M.J.; REECE, W.O. Duke's: fisiologia dos animais domésticos. 11.ed. Rio de Janeiro: Guanabara Koogan, 1996. 856p.

WARRISS, P.D. Meat science: an introductory text. Wallingford: CABI, 2000. 310p. 